\title{
P. Rossing \\ The changing epidemiology of diabetic microangiopathy in type 1 diabetes
}

Received: 15 April 2005 / Accepted: 12 May 2005 / Published online: 29 June 2005

C) Springer-Verlag 2005

\begin{abstract}
Diabetic microvascular complications in the kidney and the eye are a major burden for diabetic patients due to increased morbidity and mortality. Furthermore, diabetic nephropathy is the leading cause of end-stage renal disease and diabetic retinopathy is the leading cause of blindness in younger patients, representing a major public health concern. During the past two decades beneficial effects of, in particular, aggressive antihypertensive control and strict glycaemic control have been demonstrated in randomised controlled clinical trials. Technological improvements in diabetes care have made good metabolic control easier to achieve. Has this led to an improved prognosis? In observational studies from dedicated centres, a decrease from 47 to $13 \%$ has been reported in the incidence of proliferative diabetic retinopathy after 20-25 years of diabetes, and the incidence of overt diabetic nephropathy after 20 years has decreased from 28 to $5.8 \%$. Even functional and morphological remission of diabetic nephropathy has been reported. Despite this, recent population-based studies have failed to demonstrate a decrease in the incidence of blindness caused by diabetes, and the incidence of end-stage renal disease has progressively increased. This may, in part, be the result of a combination of increasing numbers of diabetic patients and a lag phase between improvement in management and a decline in end-stage complications. It is of concern, however, that the results from specialised centres may not apply to routine diabetes care. It is, therefore, mandatory that the beneficial effects of pharmacological and non-pharmacological interventions demonstrated in clinical trials and recommended by treatment guidelines are translated into clinical practice to ensure a widespread improvement in prognosis.
\end{abstract}

P. Rossing $(\bowtie)$

Steno Diabetes Center,

Niels Steensens Vej 2,

2820 Gentofte, Denmark

e-mail: pro@steno.dk

Tel.: +45-30-757310

Fax: $+45-44-438232$
Keywords Diabetic nephropathy - Diabetic retinopathy · Epidemiology · Microvascular complications - Review · Type 1 diabetes

\section{Introduction}

Diabetes predisposes to the development of generalised microangiopathy, with clinical consequences affecting kidney, eye and nerves [1]. Diabetic nephropathy is the leading cause of end-stage renal disease in the Western world, and is responsible for more than $40 \%$ of new cases of endstage renal disease in the USA; the proportion of patients with end-stage renal disease due to diabetes has increased during the last decades [2]. Almost all patients develop background retinopathy with time, and $40-50 \%$ progress to proliferative retinopathy within 25 years of diabetes onset [3]. Diabetic retinopathy is the most important cause of visual impairment in the Western world among individuals aged $<60$. Furthermore, the burden of macrovascular morbidity and mortality is also increased in patients suffering from microvascular disease [4-6].

New techniques for diabetes management have been introduced over the past few decades, including self-monitoring of blood glucose, long-term monitoring of glycaemic control by $\mathrm{HbA}_{1} \mathrm{c}$, basal-bolus insulin treatment and the use of insulin pen devices. These advances have been matched by improvements in blood pressure control with aggressive antihypertensive treatment, with particular focus on agents that block the renin-angiotensin system. The prevalence of smoking has also declined. The impact of these developments upon microvascular complications in type 1 diabetes that affect the kidney and eye will be reviewed in this paper.

\section{The changing course of diabetic kidney disease}

Older studies report a cumulative incidence of nephropathy in young patients of $25-40 \%$ after 25 years of diabetes; a higher incidence was noted in those diagnosed in the 1930s 
than in those diagnosed in the 1950s [7, 8]. Overt diabetic nephropathy with persistent proteinuria has traditionally had a poor prognosis, characterised by a relentless decline in renal function, development of end-stage renal failure and a median survival time of only 6-7 years after onset of nephropathy $[9,10]$. As Kussman et al. remarked in 1976, "once the clinical signs of nephropathy have become manifest, the natural course is inexorably progressive to death" [9]. There was, therefore, considerable interest in a study from Sweden that, in 1994, reported a dramatic decline in the incidence of diabetic nephropathy: the 20year cumulative incidence fell from $28 \%$ in patients with onset of type 1 diabetes from $1961-1965$ to only $5.8 \%$ in patients with onset of diabetes from 1971-1975 [11]. Furthermore, not one patient diagnosed between 1976 and 1980 developed persistent proteinuria [11]. These excellent results were probably due to the work of a dedicated team that achieved glycaemic control equivalent to that seen in an intensively treated group in the DCCT study [12]. We attempted to replicate these findings at the Steno Diabetes Center, but found no decline in the incidence of diabetic nephropathy. The difference in the results of the two studies can probably be explained by worse glucose control in the Danish cohort [13] in combination with a higher proportion of smokers - smoking is probably a risk factor for the development of diabetic nephropathy as smoking has been related to proteinuria in cross-sectional studies [14-16] and to the progression from normo- to microalbuminuria in prospective studies $[17,18]$. In contrast, a subsequent study from our centre found a marked decline in diabetic microangiopathy: the cumulative incidence of diabetic nephropathy after 20 years of diabetes decreased from $31.1 \%$ in patients with onset of diabetes from 1965-1969 to only $13.7 \%$ in those with onset of diabetes from 1979-1984 [19] (Fig. 1). The improvement was considered to be the result of earlier and more aggressive antihypertensive medication, improved glycaemic control and fewer smokers. These findings suggested that the falling cumulative incidence of diabetic nephropathy that was first detected in a single study from Sweden might have a more widespread significance.

The natural history of diabetic nephropathy has historically been associated with an inexorable increase in the urinary AER, and a decrease in the GFR of $10-15 \mathrm{ml} \mathrm{min}^{-1}$ year $^{-1}$ [20]. Two decades ago, it was demonstrated that antihypertensive treatment could delay the development of end-stage renal failure by reducing the rate of decline of the GFR [21, 22], a finding that has subsequently been confirmed in randomised controlled trials (see below). Observational studies indicate a decline in the GFR of $3.7 \mathrm{ml}$ $\min ^{-1}$ year ${ }^{-1}$ in patients on antihypertensive therapy [23]. Poor glucose control and hypercholesterolaemia have also been associated with a more rapid deterioration of kidney function in observational, but not interventional, studies $[23,24]$.

Similar findings have been reported by Nishimura et al. [25], who assessed the long-term incidence and temporal trends of end-stage renal disease in childhood-onset diabetes using a population based cohort of 1,075 type 1 diabetic patients from Allegheny County (PA, USA). Complication status was assessed in $74.2 \%$ of the cohort. These results revealed that the 20 -year cumulative incidence of end-stage renal disease fell from $9.1 \%$ in children with onset of diabetes from 1965-1969 to 3.6\% in those diagnosed from 1975-1979. The authors further reported an increase in the time to development of end-stage renal disease had increased, suggesting that not only is the incidence of end-stage nephropathy declining, but also the progression of nephropathy to chronic renal failure is at least being delayed [25]. Furthermore, median survival from onset of proteinuria has increased from 6-7 years to 14 years [26]. Even so, a recent analysis has shown that the requirement for renal replacement therapy in type 1 diabetes had risen in parallel with the $2.4 \%$ annual increase in the incidence
Fig. 1 Cumulative incidence of diabetic nephropathy in 600 type 1 diabetic patients with onset of diabetes from 1965 $1969(n=113, \bullet), 1970-1974$ $(n=130, \boldsymbol{\Delta}), 1975-1979$ $(n=113, \downarrow)$ and $1979-1984$ $(n=244, \square), p<0.001, \log$ rank test. Copyright 2003 American Diabetes Association. From Diabetes Care (2003) vol. 26:1258-1264. Reprinted with permission from The American Diabetes Association

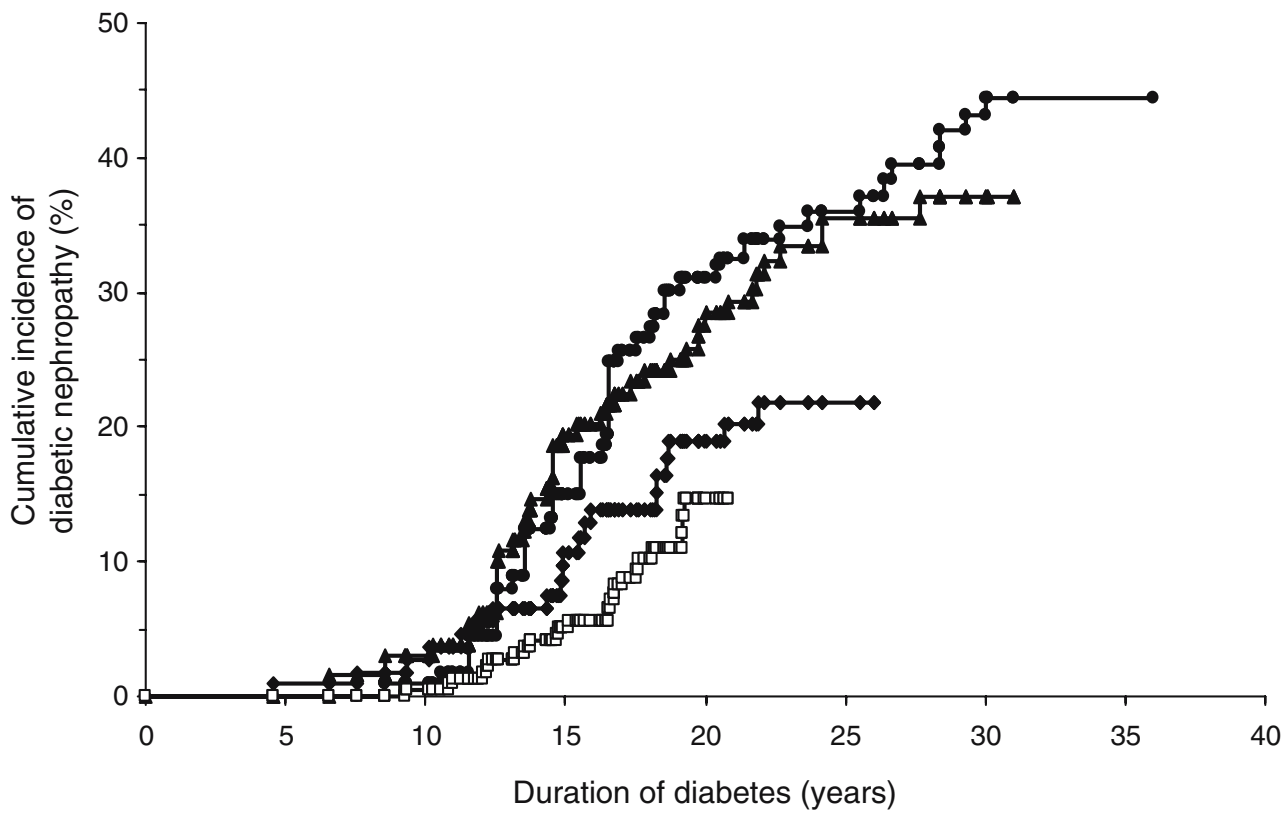


of this condition in Europe from 1991-2000 [27]. The incidence of new cases of end-stage renal failure due to diabetes has, however, plateaued since 2000 in both the USA [2] (Fig. 2) and Denmark [28].

In their paper, Kussman et al. state that diabetic nephropathy is irreversible [9]; however, the observation that morphological lesions of diabetic nephropathy can be reversed by normoglycaemia following pancreas transplantation implies that microvascular lesions in the kidney are potentially reversible [29]. Regression of the earlier stages of microalbuminuria has been demonstrated following antihypertensive treatment, and one prospective observational study reported that, over a 7.5-year follow-up period, regression occurred in $35 \%$ of 79 type 1 patients with microalbuminuria (in $39 \%$ of patients treated with an ACE inhibitor and in $13 \%$ of untreated patients). In another study, a reduction $(>50 \%)$ in the urinary AER was observed in $58 \%$ of 386 microalbuminuric type 1 diabetic patients, but this reduction was transient in many patients, the follow-up period was shorter and the drop-out rate was $47 \%$ [30].

Remission of overt diabetic nephropathy has been defined as a sustained $(>1$ year) reduction in the urinary AER to microalbuminuric levels or less $(<200 \mu \mathrm{g} / \mathrm{min})$, and regression of nephropathy has been defined as a decrease in the GFR of $1 \mathrm{ml} \mathrm{min}^{-1}$ year $^{-1}$ (corresponding to normal adult loss of renal function) [31]. An observational study that followed 301 type 1 diabetic subjects with overt diabetic nephropathy for 7 years (range 3-14 years) found remission of nephropathy in $31 \%$ of patients and regression of nephropathy in $22 \%$; this was attributed to aggressive antihypertensive treatment [31]. Patients with nephrotic-range proteinuria have the worst prognosis in terms of loss of renal function and survival, but remission of proteinuria has been observed even in this group of patients [32]. In a recent study, the urinary AER of $22 \%$ of those with nephrotic-range albuminuria $(>2500 \mathrm{mg} / 24 \mathrm{~h})$ was reduced to less than $600 \mathrm{mg} / 24 \mathrm{~h}$, with a resultant decrease in the rate of decline of the GFR, and - more importantly-improved survival [33].

These improvements in the prognosis for type 1 diabetic patients with nephropathy are most likely due to develop- ments in patient management, in particular the use of early and aggressive antihypertensive therapy. Initial studies demonstrated that aggressive antihypertensive treatment delayed the development of end-stage renal failure in type 1 diabetic patients with diabetic kidney disease by reducing the loss of renal function [21, 22]. More recent randomised controlled studies have suggested that intervention targeting the renin-angiotensin system is particularly renoprotective, i.e. preserves renal function above and beyond the effect of lowering blood pressure $[34,35]$.

ACE inhibition has also been tested at an earlier stage to determine whether it has a protective effect against the development of microalbuminuria in normoalbuminuric patients. This could not be confirmed in the EURODIAB Controlled Trial of Lisinopril in Insulin Dependent Diabetes (EUCLID), which enrolled 440 normoalbuminuric type 1 diabetic patients [36]. However, this unsuccessful attempt at primary prevention is in contrast with the success in secondary prevention demonstrated in a meta-analysis suggesting that ACE inhibitors reduce progression from microalbuminuria to overt nephropathy by $62 \%$. A three-fold increase in the rate of regression of microalbuminuria to normoalbuminuria was seen in patients treated with ACE inhibitors, as compared with placebo-treated patients [37]. Preservation of GFR for up to 8 years has been demonstrated in microalbuminuric patients receiving an ACE inhibitor [38].

\section{Changes in diabetic retinopathy}

The initial Swedish study [11] that reported a marked decline in diabetic kidney disease with time found no effect on retinopathy [39]. Recently, a follow-up study of the same population $(n=269)$ found a significant decline in severe retinopathy after 25 years, from 47 to $24 \%$, in cohorts with onset of diabetes from 1961-1965 and 19711975, respectively [40]. In patients with onset from 1976 1985 , there was a trend for further improvement, but the majority of patients still developed background retinopathy [40]. Another Swedish study found that the incidence of blindness due to diabetes in Stockholm county fell by
Fig. 2 Rates of development of end-stage renal disease in the USA (per million population) from 1992-2002 according to primary diagnosis [2]. $\downarrow$, diabetes; $\boldsymbol{\Delta}$, hypertension; $\mathbf{\square}$, glomerulonephritis; $x$ cystic kidney disease. The data reported here have been supplied by the United States Renal Data System (USRDS). The interpretation and reporting of these data are the responsibility of the author(s) and in no way should be seen as an official policy or interpretation of the US

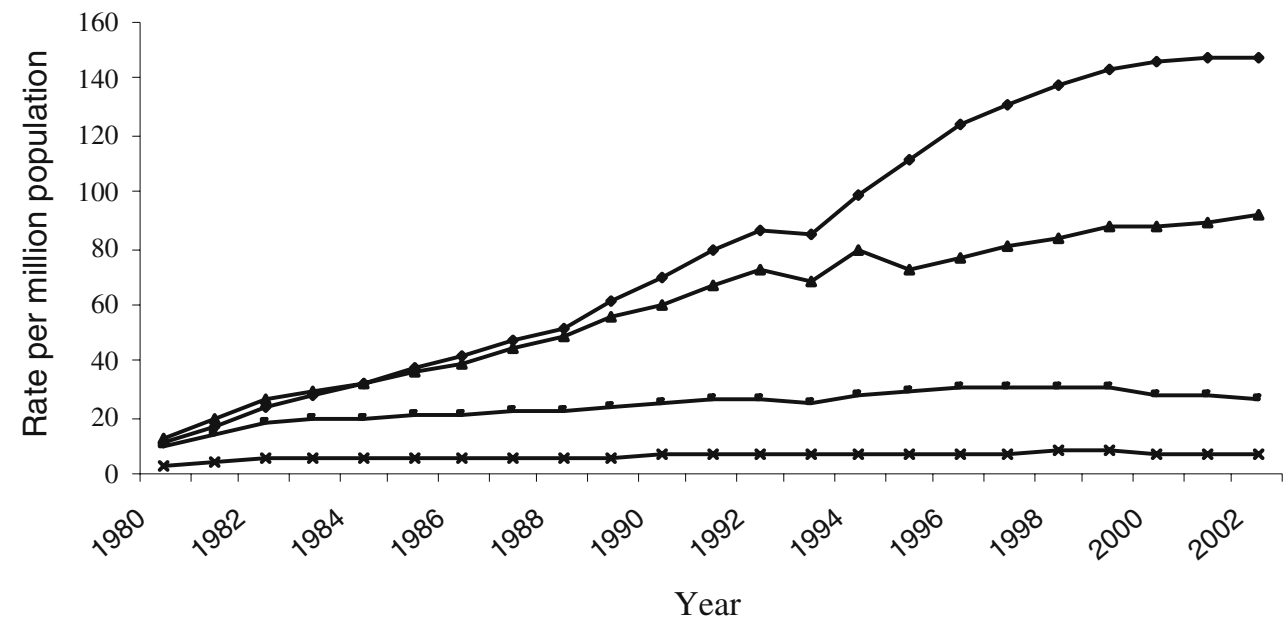


more than $50 \%$ over a 15 -year period [41]. In contrast, from 1990-1998, there was no significant change in the incidence of blindness due to diabetes in the district of Württemberg-Hohenzollern, a German district with a population of 5 million [42]. A Danish study, meanwhile, found that the cumulative incidence of proliferative diabetic retinopathy after 20 years of diabetes declined from 31.2 to $12.5 \%$, with a decline in maculopathy from 18.6 to $7.4 \%$ observed over the same time period [43]. There was a parallel improvement in visual acuity in more recent cohorts [44]. Unfortunately, larger population-based data on changes in the incidence of earlier stages of diabetic retinopathy are lacking.

Prevention of initiation of diabetic retinopathy, i.e. primary prevention of diabetic retinopathy, is most likely achieved through improvements in glycaemic control, as demonstrated in the primary prevention cohort in the DCCT study [12]. It is possible that control of blood pressure is also important in type 1 diabetic patients, as shown for type 2 diabetic patients in the UK Prospective Diabetes Study (UKPDS) [45]. However, as mentioned above, even among patients with good glycaemic control, a substantial number will develop background retinopathy [40].

For secondary prevention, i.e. progression of retinopathy to potentially sight-threatening complications, glycaemic control is also very important, as demonstrated in the secondary intervention cohort of the DCCT study [12]. The declining incidence of proliferative retinopathy, described above, can probably be explained by improved glycaemic control, but it is also likely that improved blood pressure control played an important role. As in the kidney, there has been interest in the potential additive benefit of ACE inhibition upon microvascular lesions in the eye [46]. Randomisation of normotensive patients with type 1 diabetes to ACE inhibition in the EUCLID study reduced the risk of progressing one level on the retinopathy scale by $50 \%$, and reduced the risk of the development of proliferative retinopathy by $82 \%$ [47]. This has not yet been confirmed in other studies, but the ongoing Diabetic Retinopathy Candesartan Trial (DIRECT) aims to evaluate what effect blockade of the renin-angiotensin system with an angiotensin II receptor blocker has on the initiation and progression of diabetic retinopathy in type 1 and type 2 diabetes.

For tertiary prevention, i.e. loss of vision or development of blindness, laser treatment has been the cornerstone of treatment designed to prevent or delay loss of vision in those with proliferative diabetic retinopathy [48, 49], preferably in the early stages. Thus, regular screening is mandatory if a reduction in blindness is to be attained. It has also been suggested in some cases of very severe nonproliferative retinopathy [50], and is also successful in the treatment of macular oedema [51]. In the most severe cases with retinal traction, surgery with vitrectomy may improve the visual prognosis [52].

\section{The increasing prevalence of susceptible patients}

While studies from specialised centres have demonstrated a decline in the cumulative incidence of microvascular complications, the number of patients presenting with end-stage renal disease in the USA [2] (Fig. 2) and Europe [27] has increased in recent decades. How can this be explained? One note of caution is that results obtained in specialised centres should not be generalised to more routine diabetes care. Another likely reason is the increasing incidence of type 1 diabetes - the reduction in the individual risk of progression may have been counterbalanced by an increase in the total number of individuals at risk.

\section{Conclusion}

Observational studies from dedicated centres have shown that the individual risk of developing microvascular complications has fallen in recent years as a consequence of improvements in diabetes management. These improvements include aggressive antihypertensive therapy and improved glycaemic control; the benefits of both interventions have been well demonstrated in randomised clinical trials. Even so, the number of patients suffering from endstage renal disease has increased. It is, therefore, mandatory that the beneficial effects of pharmacological and non-pharmacological interventions demonstrated in clinical trials and recommended by treatment guidelines are translated into clinical practice to ensure a widespread improvement in prognosis.

\section{References}

1. Tesfaye S, Chaturvedi N, Eaton SEM et al (2005) Vascular risk factors and diabetic neuropathy. N Engl J Med 352:341-350

2. United States Renal Data System (2004) USRDS annual data report 2004. National Institute of Diabetes and Digestive and Kidney Diseases, Bethesda, MD

3. Klein R, Klein BE, Moss SE, Davis MD, DeMets DL (1984) The Wisconsin epidemiologic study of diabetic retinopathy: II. Prevalence and risk of diabetic retinopathy when age at diagnosis is less than 30 years. Arch Ophthalmol 102:520-526

4. Borch-Johnsen K, Kreiner S (1987) Proteinuria: value as predictor of cardiovascular mortality in insulin dependent diabetes mellitus. BMJ 294:1651-1654

5. Dinneen SF, Gerstein HC (1997) The association of microalbuminuria and mortality in non-insulin-dependent diabetes mellitus. Arch Intern Med 157:1413-1418

6. Rossing P, Hougaard P, Borch-Johnsen K, Parving H-H (1996) Predictors of mortality in insulin dependent diabetes: 10 year follow up study. BMJ 313:779-784

7. Krolewski AS, Warram JH, Christlieb AR, Busick EJ, Kahn CR (1985) The changing natural history of nephropathy in Type 1 diabetes. Am J Med 78:785-794

8. Kofoed-Enevoldsen A, Borch-Johnsen K, Kreiner S, Nerup J, Deckert T (1987) Declining incidence of persistent proteinuria in type 1 (insulin-dependent) diabetic patients in Denmark. Diabetes 36:205-209

9. Kussman MJ, Goldstein HH, Gleason RE (1976) The clinical course of diabetic nephropathy. JAMA 236:1861-1863 
10. Andersen AR, Christiansen JS, Andersen JK, Kreiner S, Deckert T (1983) Diabetic nephropathy in Type 1 (insulindependent) diabetes: an epidemiological study. Diabetologia 25:496-501

11. Bojestig M, Arnqvist HJ, Hermansson G, Karlberg B, Ludvigsson J (1994) Declining incidence of nephropathy in insulin-dependent diabetes mellitus. N Engl J Med 330:15-18

12. The Diabetes Control and Complications Trial Research Group. (1993) The effect of intensive treatment of diabetes on the development and progression of long-term complications in insulin-dependent diabetes mellitus. N Engl J Med 329:977986

13. Rossing P, Rossing K, Jacobsen P, Parving H-H (1995) Unchanged incidence of diabetic nephropathy in IDDM patients. Diabetes 44:739-743

14. Telmer S, Christiansen JS, Andersen AR, Nerup J, Deckert T (1984) Smoking habits and prevalence of clinical diabetic microangiopathy in insulin-dependent diabetics. Acta Med Scand 215:63-68

15. Nordén G, Nyberg G (1984) Smoking and diabetic nephropathy. Acta Med Scand 215:257-261

16. Mühlhauser I, Sawicki PT, Berger M (1986) Cigarette smoking as a risk factor for macroproteinuria and proliferative retinopathy in Type 1 (insulin-dependent) diabetes. Diabetologia 29: 500-502

17. Chase HP, Garg SK, Marshall G et al (1991) Cigarette smoking increases the risk of albuminuria among subjects with type 1 diabetes. JAMA 265:614-617

18. Rossing P, Hougaard P, Parving HH (2002) Risk factors for development of incipient and overt diabetic nephropathy in type 1 diabetic patients: a 10-year prospective observational study. Diabetes Care 25:859-864

19. Hovind P, Tarnow L, Rossing K et al (2003) Decreasing incidence of severe diabetic microangiopathy in type 1 diabetes. Diabetes Care 26:1258-1264

20. Rossing P, Hommel E, Smidt UM, Parving H-H (1993) Impact of arterial blood pressure and albuminuria on the progression of diabetic nephropathy in IDDM patients. Diabetes 42:715-719

21. Parving H-H, Andersen AR, Smidt UM, Svendsen PA (1983) Early aggressive antihypertensive treatment reduces rate of decline in kidney function in diabetic nephropathy. Lancet $1: 1175-1179$

22. Mogensen CE (1982) Long-term antihypertensive treatment inhibiting progression of diabetic nephropathy. Br Med J 285: 685-688

23. Hovind P, Rossing P, Tarnow L, Smidt UM, Parving H-H (2001) Progression of diabetic nephropathy. Kidney Int 59:702-709

24. Mulec H, Johnsen SA, Björck S (1990) Relation between serum cholesterol and diabetic nephropathy. Lancet 335:15371538

25. Nishimura R, Dorman JS, Bosnyak Z, Tajima N, Becker DJ, Orchard TJ (2003) Incidence of ESRD and survival after renal replacement therapy in patients with type 1 diabetes: a report from the Allegheny County Registry. Am J Kidney Dis 42:117124

26. Rossing P, Hougaard P, Borch-Johnsen K, Parving H-H (1996) Predictors of mortality in insulin dependent diabetes: 10 year follow-up study. BMJ 313:779-784

27. Van Dijk PCW, Jager KJ, Stengel B, Gronhagen-Riska C, Feest TG, Briggs JD (2005) Renal replacement therapy for diabetic end-stage renal disease: data from 10 registries in Europe (1991-2000). Kidney Int 67:1489-1499

28. Danish Society of Nephrology (2004) Danish National Registry Report on Dialysis and Transplantation in Denmark 2003. Paritas Grafik A/S, Denmark

29. Fioretto P, Steffes MW, Sutherland DER, Goetz FC, Mauer M (1998) Reversal of lesions of diabetic nephropathy after pancreas transplantation. N Engl J Med 339:69-75

30. Perkins BA, Ficociello LH, Silva KH, Finkelstein DM, Warram JH, Krolewski AS (2003) Regression of microalbuminuria in type 1 diabetes. N Engl J Med 348:2285-2293
31. Hovind P, Rossing P, Tarnow L, Smidt UM, Parving H-H (2001) Remission and regression in the nephropathy of type 1 diabetes when blood pressure is controlled aggressively. Kidney Int 60:277-283

32. Hebert LA, Bain RP, Verme D et al (1994) Remission of nephrotic-range proteinuria in type I diabetes. Kidney Int 46:16881693

33. Hovind P (2004) Improved survival in patients obtaining remission of nephrotic range albuminuria in diabetic nephropathy. Kidney Int 66:1180

34. Björck S, Johnsen SA, Nyberg G, Aurell M (1990) Contrasting effects of enalapril and metoprolol on proteinuria in diabetic nephropathy. BMJ 300:904-907

35. Lewis EJ, Hunsicker LG, Bain RP, Rohde RD (1993) The effect of angiotensin-converting-enzyme inhibition on diabetic nephropathy. The Collaborative Study Group. N Engl J Med 329:1456-1462

36. Chaturvedi N (1997) Randomised placebo-controlled trial of lisinopril in normotensive patients with insulin-dependent diabetes and normoalbuminuria or microalbuminuria. Lancet 349 : $1787-1792$

37. Chaturvedi N (2001) Should all patients with type 1 diabetes mellitus and microalbuminuria receive angiotensin-converting enzyme inhibitors? A meta-analysis of individual patient data. Ann Intern Med 134:370-379

38. Mathiesen ER, Hommel E, Hansen HP, Smidt UM, Parving H-H (1999) Preservation of normal GFR with long term captopril treatment in normotensive IDDM patients with microalbuminuria. BMJ 319:24-25

39. Bojestig M, Arnqvist HJ, Karlberg BE, Ludvigsson J (1998) Unchanged incidence of severe retinopathy in a population of Type 1 diabetic patients with marked reduction of nephropathy. Diabet Med 15:863-869

40. Nordwall M, Bojestig M, Arnqvist HJ, Ludvigsson J (2004) Declining incidence of severe retinopathy and persisting decrease of nephropathy in an unselected population of Type 1 diabetes - the Linkoping Diabetes Complications Study. Diabetologia 47:1266-1272

41. Bäcklund LB, Algvere PV, Rosenqvist U (1997) New blindness in diabetes reduced by more than one-third in Stockholm County. Diabet Med 14:732-740

42. Trautner C (2001) Incidence of blindness in southern Germany between 1990 and 1998. Diabetologia 44:147-150

43. Hovind P, Tarnow L, Rossing K et al (2003) Decreasing incidence of severe diabetic microangiopathy in type 1 diabetes. Diabetes Care 26:1258-1264

44. Rossing K, Jacobsen P, Rossing P, Lauritzen E, Lund-Andersen $\mathrm{H}$, Parving H-H (1998) Improved visual function in IDDM patients with unchanged cumulative incidence of sightthreatening diabetic retinopathy. Diabetes Care 21:2007-2015

45. UK Prospective Diabetes Study (UKPDS) Group (1998) Efficacy of atenolol and captopril in reducing risk of macrovascular and microvascular complications in type 2 diabetes: UKPDS 39. BMJ 317:713-720

46. Larsen M, Hommel E, Parving H-H, Lund-Andersen H (1990) Protective effect of captopril on the blood-retina barrier in normotensive insulin-dependent diabetic patients with nephropathy and background retinopathy. Graefe Arch Clin Exp Ophthalmol 228:505-509

47. Chaturvedi N, Sjolie A-K, Stephenson JM et al (1998) Effect of lisinopril on progression of retinopathy in normotensive people with type 1 diabetes. Lancet 351:28-31

48. The Diabetic Retinopathy Study Research Group (1981) Photocoagulation treatment of proliferative diabetic retinopathy. Clinical application of Diabetic Retinopathy Study (DRS) findings, DRS Report Number 8. Ophthalmology 88:583-600

49. British Multicentre Study Group (1983) Photocoagulation for diabetic maculopathy. A randomized controlled clinical trial using the xenon arc. Diabetes 32:1010-1016 
50. Flynn HW Jr (1992) Pars plana vitrectomy in the Early Treatment Diabetic Retinopathy Study. ETDRS report number 17. The Early Treatment Diabetic Retinopathy Study Research Group. Ophthalmology 99:1351

51. Early Treatment Diabetic Retinopathy Study Research Group (1987) Treatment techniques and clinical guidelines for photocoagulation of diabetic macular edema. Early treatment diabetic retinopathy study report number 2 . Ophthalmology 94 : 761-774
52. The Diabetic Retinopathy Vitrectomy Study Research Group (1985) Early vitrectomy for severe vitreous hemorrhage in diabetic retinopathy. Two-year results of a randomized trial. Diabetic Retinopathy Vitrectomy Study report 2. Arch Ophthalmol 103:1644-1652 